\title{
Prognostic Factors in the Management of Exacerbation of Chronic Obstructive Pulmonary Disease in Kuwait
}

\author{
B.O. Onadeko ${ }^{a}$ M. Khadadaha N. Abdella ${ }^{a}$ M. Mukhtar ${ }^{b}$ M. Mourou ${ }^{b}$ \\ M. Qurtom ${ }^{\text {b }}$ M. Samad ${ }^{b}$ A. Al-Shayeb ${ }^{b}$

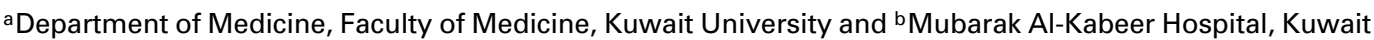

\section{Key Words}

Chronic obstructive pulmonary disease - Exacerbation • Management · Prognostic factors · Kuwait

\begin{abstract}
Objective: To evaluate the clinical presentation and the factors of prognostic importance in the management of exacerbation of chronic obstructive pulmonary disease (COPD). Subjects and Methods: One hundred and four patients who were hospitalized because of exacerbation of COPD between 1996 and 2000 were selected for further evaluation. Only patients who fulfilled the American Thoracic Society criteria for diagnosis of COPD were included. The factors examined included age, clinical features, duration of symptoms of exacerbation, severity of underlying disease, comorbid diseases, level of consciousness, previous hospitalization, intubation and assisted ventilation, hypercapnia, degree of acidemia and complications. Results: Seventy-four of 104 (71\%) hospitalized patients reviewed met the inclusion criteria for COPD. The mean age was $63.68 \pm 12.6$ years. There was a male:female ratio of $3: 1$. Fifty-eight patients (78\%) had a baseline $\mathrm{FEV}_{1}<50 \%$ before hospitalization and 45 (64\%) had previous hospitalization. Comorbid disease was found in $50 \%$ of the cases, while $78 \%$ had acidemia
\end{abstract}

and $70 \%$ hypercapnia. Fourteen (19\%) died on admission. Risk factors identified included severity of disease $(p<0.05)$; presence of comorbid disease $(p<0.01)$; acidemia ( $<0.0001)$; hypercapnia $(p<0.0001)$; previous hospitalization ( $p<0.01$ ), and assisted ventilation ( $p<$ 0.001). Conclusion: This study revealed that the presence of comorbid disease, acidemia, previous hospitalization and assisted ventilation significantly contributed to mortality in patients with exacerbation of COPD.

Copyright $\odot 2005$ S. Karger AG, Basel

\section{Introduction}

Chronic obstructive pulmonary disease (COPD) is a major cause of chronic morbidity and mortality worldwide [1]. It is currently the fourth leading cause of death in the world, and further increases in the prevalence and mortality of the disease could be predicted in the coming decades [2]. The major characteristic of COPD is the presence of chronic airflow limitation that progresses slowly over a period of years and is largely irreversible [3]. Several national and international consensus statements have led to international standardization of diagnosis, management and better care [2-4].

Prof. B.O. Onadeko

PO Box 29279

Secretariat Post Office

Ibadan, Oyo State (Nigeria)

Tel./Fax +9652342 8100556, E-Mail onadeko@hotmail.com
Fax +4161306 1234

E-Mail karger@karger.ch

www. karger.com

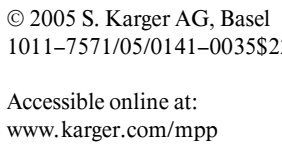


Table 1. Age distribution according to agegroups

\begin{tabular}{lcc}
\hline Age group & Cases & $\%$ \\
\hline$<50$ & $8(1)$ & 10.81 \\
$51-60$ & $18(2)$ & 24.32 \\
$61-70$ & $27(4)$ & 36.49 \\
$>70$ & $21(7)$ & 28.38 \\
\hline Total & $74(14)$ & 100 \\
\hline
\end{tabular}

Number of deaths in parentheses.

Table 2. Hydrogen ion concentration $(\mathrm{pH})$ on presentation

\begin{tabular}{lc}
\hline $\mathrm{pH}$ & Cases \\
\hline$>7.4$ & 13 \\
$7.25-7.35$ & 26 \\
$7.11-7.24$ & 9 \\
$7.0-7.10$ & 6 \\
$<7.0$ & 4 \\
\hline
\end{tabular}

Exacerbation of COPD is the largest single cause of emergency respiratory admission, accounting for $21 \%$, with a mean hospital stay of 10.3 days in the United Kingdom [5]. Knowledge of prognosis in COPD is mainly derived from studies of carefully selected patient groups. These studies have shown that prognosis is related to age and other lung function indices [6-10]. Hospitalization for acute exacerbation usually occurs in the advanced phase of the disease and is thus associated with a greater risk of mortality in subsequent years [11, 12].

COPD is a rather common disease in Kuwait. The prevalence and frequency of hospitalization of patients have increased in the last two decades, attributable to increased industrial activities and cigarette smoking [13]. This study therefore aims at evaluating some of the factors which may contribute to hospitalization and mortality in these patients. Suggestions towards improving the management of these patients before and during exacerbations are made.

\section{Subjects and Methods}

One hundred and four case files of patients hospitalized during exacerbations at Mubarak Al-Kabeer Hospital, Kuwait, a tertiary medical center over a 5-year period (1996-2000) were reviewed. Patients with diagnosis consistent with asthma, bronchiectasis, and left ventricular failure were excluded from the study. Seventy-four patients who fulfilled the American Thoracic Society [3] criteria for diagnosis of COPD were selected for further data analysis. Data retrieved included baseline forced expiratory volume in $1 \mathrm{~s}\left(\mathrm{FEV}_{1}\right)$ at diagnosis of the disease, duration of the underlying disease, presenting symptoms of exacerbation and history of cigarette smoking, precipitating factors leading to exacerbation, comorbid diseases, history of previous hospitalization, level of consciousness on admission, drug therapy and drug compliance before exacerbation. Physical signs at presentation were recorded. Other data collected included use of home oxygen, arterial blood gases at presentation, chest radiograph and findings, and electrocardiograph records on admission. The types of drugs given during hospitalization were also recorded. Records of management in the intensive care unit, with or without mechanically assisted ventilation, were noted. History of previous intubation and assisted ventilation was also recorded. Complications developed during management, duration of stay in hospital and outcome of the illness were also noted.

Statistical Analysis

A univariate analysis of each variable was performed. Confidence intervals (CIs) for odds ratio (OR) of significant variables were calculated for the risk factors. Values of $p<0.05$ were considered statistically significant.

\section{Results}

Table 1 shows age distribution; mean age was $63.68 \pm$ 12.6 years and the male:female ratio was $3: 1$. The mean duration of symptoms before admission was 3 days. Fiftyeight of the 104 (78\%) patients had a moderate to severe underlying disease. The $\mathrm{FEV}_{1}$ on diagnosis for the moderate $(45 \%)$ and severe cases $(40 \%)$ was $35-40 \%$ and $<35 \%$ of the predicted value, respectively. History of cigarette smoking was present in $54(73 \%)$ patients. Only 20 patients did not smoke cigarettes.

The predominant precipitating factor for exacerbation was respiratory tract infection in $81 \%$ of the cases. Comorbid diseases occurred in $50 \%$ of the patients, the most common being ischemic heart disease; the rest were diabetes mellitus, obesity and sleep apnea syndrome, chronic renal failure, chronic liver disease and cerebrovascular disease. Acidemia was observed at presentation in $77 \%$ of cases. Nine patients had a $\mathrm{pH}$ of 7.0 and below. Hypercapnia occurred in $70 \%$ of the cases, the highest partial pressure of carbon dioxide recorded being $17.2 \mathrm{kPa}$ (table 2).

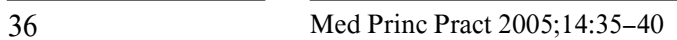

Onadeko/Khadadah/Abdella/Mukhtar/

Mourou/Qurtom/Samad/Al-Shayeb 
Table 3. Factors contributing to death in patients with exacerbation of COPD

\begin{tabular}{|c|c|c|c|c|}
\hline Variables & $\begin{array}{l}\text { Alive } \\
(\mathrm{n}=60)\end{array}$ & $\begin{array}{l}\text { Dead } \\
(n=14)\end{array}$ & $\begin{array}{l}\text { OR } \\
(95 \% \mathrm{CI})\end{array}$ & $\mathrm{p}$ value \\
\hline \multicolumn{5}{|l|}{ Age } \\
\hline$>65$ years & & 8 & 1.21 & \multirow[t]{2}{*}{0.78} \\
\hline$<65$ years & & 6 & $(0.37-3.93)$ & \\
\hline \multicolumn{5}{|l|}{ Sex } \\
\hline Male & 46 & 10 & 1.31 & \multirow[t]{2}{*}{0.77} \\
\hline Female & 14 & 4 & $(0.23-2.60)$ & \\
\hline \multicolumn{5}{|c|}{ Severity of underlying disease } \\
\hline $\mathrm{FEV}_{1}<50 \%$ predicted & 33 & 13 & 0.09 & \multirow{2}{*}{$<0.05$} \\
\hline $\mathrm{FEV}_{1}>50 \%$ predicted & 27 & 1 & $(0.01-0.77)$ & \\
\hline \multicolumn{5}{|c|}{ Duration of symptoms before hospitalization } \\
\hline$>3$ days & 35 & 9 & 0.78 & \multirow[t]{2}{*}{0.77} \\
\hline$<3$ days & 25 & 5 & $(0.23-2.60)$ & \\
\hline \multicolumn{5}{|l|}{ Comorbid disease } \\
\hline Present & 22 & 12 & 0.10 & \multirow[t]{2}{*}{$<0.01$} \\
\hline Absent & 38 & 2 & $(0.02-0.47)$ & \\
\hline \multicolumn{5}{|l|}{$\mathrm{pH}$} \\
\hline$<7.30$ & 15 & 13 & 0.03 & \multirow[t]{2}{*}{$<0.0001$} \\
\hline$>7.30$ & 45 & 1 & $(0.003-0.21)$ & \\
\hline \multicolumn{5}{|l|}{$\mathrm{pCO}_{2}$} \\
\hline$>6.0 \mathrm{kPa}$ & 15 & 12 & 0.06 & \multirow[t]{2}{*}{$<0.0001$} \\
\hline$<6.0 \mathrm{kPa}$ & 45 & 2 & $(0.01-0.28)$ & \\
\hline \multicolumn{5}{|l|}{ Level of consciousness } \\
\hline Drowsy & 10 & 8 & 0.15 & \multirow[t]{2}{*}{$<0.01$} \\
\hline Alert & 50 & 6 & $(0.04-0.53)$ & \\
\hline \multicolumn{5}{|l|}{ Previous hospitalization } \\
\hline Yes & 5 & 10 & 0.09 & \multirow[t]{2}{*}{$<0.01$} \\
\hline No & 45 & 4 & $(0.02-0.34)$ & \\
\hline \multicolumn{5}{|c|}{ Intubation/assisted ventilation } \\
\hline Yes & 10 & 10 & 0.09 & \multirow[t]{2}{*}{$<0.01$} \\
\hline No & 50 & 4 & $(0.02-0.34)$ & \\
\hline \multicolumn{5}{|l|}{ Complications } \\
\hline Yes & 9 & 9 & 0.10 & \multirow[t]{2}{*}{$<0.0001$} \\
\hline No & 51 & 5 & $(0.03-0.36)$ & \\
\hline \multicolumn{5}{|l|}{ Domiciliary $\mathrm{O}_{2}$ (LTOT) } \\
\hline Yes & 10 & 3 & 0.73 & \multirow[t]{2}{*}{0.70} \\
\hline No & 50 & 11 & $(0.17-3.12)$ & \\
\hline \multicolumn{5}{|l|}{ Oral corticosteroids } \\
\hline Yes & 19 & 3 & 1.70 & \multirow[t]{2}{*}{0.53} \\
\hline No & 41 & 11 & $(0.42-6.81)$ & \\
\hline
\end{tabular}


Twenty (26\%) of the patients were admitted to the intensive care unit and were intubated and mechanically ventilated. Fourteen patients had fatal outcome and of these, 9 had assisted ventilation. Seventy-one percent of the patients had at least one previous hospitalization, 10 of the 14 who died belonged to this category.

Complications were recorded in 18 (24\%) patients, the commonest being congestive heart failure. The duration of hospitalization varied, the majority remained in hospital for 7-14 days. Factors that were observed to affect mortality are shown in table 3 . These included severity of underlying disease as judged by $\mathrm{FEV}_{1}(\mathrm{p}<0.05)$, acidemia $(\mathrm{p}<0.0001)$, comorbid diseases $(\mathrm{p}<0.01), \mathrm{PaCO}_{2}(\mathrm{p}<$ $0.0001)$, previous hospitalization $(\mathrm{p}<0.01)$, intubation and assisted ventilation $(\mathrm{p}<0.001)$.

\section{Discussion}

The outcome of patients hospitalized with exacerbation of COPD is dependent on a number of factors including severity of the underlying disease, presence of comorbidity and frequency of hospitalization [11, 14-18]. In this study, age was not observed to be prognostically related to mortality as reported in a recent North American study [18]. However, the Canadian guidelines for COPD [15] recommended that age above 65 is a prognostic factor for COPD mortality. It is worth noting that $60 \%$ of patients who died in our study during hospitalization were above the age of 65 .

In this study, the severity of the underlying disease, as judged by the value of $\mathrm{FEV}_{1}$, was associated with poor prognosis consistent with previous reports [14, 16-18]. Thirteen of the patients with fatal outcome had FEV 1 of less than $50 \%$ predicted value. Dewan et al. [18] in a recent study showed that patients with $\mathrm{FEV}_{1}<35 \%$ predicted value had a poor prognosis. Comorbidity was found to be a significant prognostic factor in this study $(\mathrm{p}<0.001)$ similar to other studies $[14,19]$, but Dewan et al. [18] reported that comorbidity, just as age, did not affect the treatment outcome. Hospitalization for acute exacerbation of COPD usually occurs in the advanced phase of disease and is thus associated with a greater risk of mortality in subsequent years [10-12, 18].

In this study, our observation that frequent hospitalization was associated with fatal outcome $(p<0.05)$ is in agreement with previous reports $[10,12,18,20]$, which showed that repeated hospitalization accompanied by intubation and assisted ventilation was a poor prognostic factor for mortality. Noninvasive positive pressure venti- lation was not used to ventilate any of the patients who were intubated. This facility was not available at our center during the period of the study. However, it has become available now for treating COPD patients with mild to moderate exacerbation, thus reducing the need for intubation, and improving patients' quality of life.

Smoking is the most common etiological factor, associated with the disease in $75 \%$ of the patients in agreement with other studies $[21,22]$. Occupational exposure and/or atmospheric pollution have not yet been seriously associated as etiological factors in this environment, but they may feature prominently in decades to come, as many more industries emerge in Kuwait. These factors have, however, been well established in other studies [23]. One patient, below the age of 40 , in this study had $\alpha$-antitrypsin deficiency associated with CDPD. This association has been well established by Larson and Barman [24].

Hypercapnia and acidemia were the other factors of significant prognostic significance in this study similar to previous studies [25-27]. Plank et al. [25] observed that $20-47 \%$ of patients have $\mathrm{CO}_{2}$ retention at presentation and $20 \%$ may be acidotic on admission.

Corticosteroids have been shown to improve $\mathrm{FEV}_{1}$ and shorten the median hospital stay [27-29]. It is conceivable that the limited use of systemic steroids in this study $(26 \%)$ may be a contributory factor in patients with poor outcome. However, all the patients in this study were on maintenance therapy of inhaled corticosteroids (beclomethasone dipropionate) in doses ranging from 450 to $800 \mu \mathrm{g}$ daily. Some studies have demonstrated improvement in $\mathrm{FEV}_{1}$ after administration of inhaled corticosteroids to stable COPD patients [30, 31].

The findings from this study revealed that despite the severity of the underlying illness, many of the patients did not use domiciliary oxygen before admission. This was observed to be a significant factor. Garcia-Aymerich et al. [32] have shown that underprescription of long-term oxygen therapy (LTOT) was independently associated with a higher risk of admission for a COPD exacerbation, whereas the use of LTOT was associated with a lower risk of admission. A reduced mortality has been reported in earlier studies $[33,34]$ when oxygen supplementation was used for at least $15 \mathrm{~h}$ per day, but another study [35] concluded that home oxygen therapy had not shown convincing evidence that it alters exacerbation rate.

It was observed from the records that most of the patients failed to attend the outpatients follow-up clinics regularly, making it difficult to monitor their clinical status. Many of these patients reported at the emergency room only when in severe exacerbations. In fact, $60 \%$ of

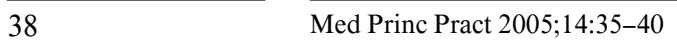


patients who succumbed were admitted in a drowsy or comatose condition. The lack of a home and social support system, which is critical to the long-term management of these patients, was probably responsible for their inability to attend an outpatient clinic for follow-up and frequent hospitalization.

Based on the findings of this study we recommend pulmonary rehabilitation after hospitalization, and use of domiciliary oxygen for patients with severe underlying disease. These measures will benefit the patients, thereby reducing the frequency of exacerbations, and consequently improve the quality of life. Home, psychological, and social support should be developed in order to improve patients' compliance with drug therapy. Finally, recent evidence now suggests that mucolytics and antioxidants may have some benefits in reducing exacerbation rate [36, 37]. There is also new evidence that introduction of the newer long-acting inhaled anticholinergics in stable state reduces dyspnea and frequency of disease exacerbations, in addition to improving the quality of life $[38,39]$. Furthermore, early recognition of patients at particular risk may reduce considerably the morbidity and mortality from complications associated with COPD exacerbations.

\section{Conclusion}

In conclusion, this study has highlighted some of the factors which lead to poor outcome in the management of patients hospitalized for exacerbation of COPD. The occurrence and/or frequency of some of these factors can be reduced or eliminated by the concerted efforts of patients, their relations and the attending physicians. It is necessary to introduce and implement appropriate measures, which will assist to reduce significantly the burden of COPD in this environment.

\section{Acknowledgment}

We are indebted to the staff of the Medical Records Department who made the case files available. We thank the Medical Director of Mubarak Al-Kabeer Hospital for giving permission for this study. The contribution of Mrs. Ajitha Suresh is acknowledged for her assistance with the statistical analysis.

\section{References}

1 Hurd S: The impact of COPD on lung health world wide: Epidemiology and incidence. Chest 2000;117(suppl 2):1s-4s.

2 NHLB1/WHO Global Initiative for Chronic Obstructive Lung Disease. GOLD 2001, p 1.

3 Standards for the diagnosis and care of patients with chronic obstructive pulmonary disease. American Thoracic Society. Am J Respir Crit Care Med 1995;152:S77-S120.

4 BTS guidelines for management of chronic obstructive pulmonary disease. The COPD Guidelines Group of the Standards of Care Committee of the BTS. Thorax 1997;52(suppl): S1-S28.

5 Roberts CM, Ryland I, Lowe D, Kelly Y, Bucknall CE, Pearson MG: Audit of acute admissions of COPD: Standards of care and management in the hospital setting. Eur Respir J 2000; 17:243-349.

-6 Boushy SF, Thompson HK, North LB, Beale AR, Snow TR: Prognosis in chronic obstructive pulmonary disease. Am Rev Respir Dis 1973; 108:1373-1383.

7 Traver GA, Cline MG, Burrows B: Predictors of mortality in chronic obstructive pulmonary disease: A 15-year follow-up study. Am Rev Respir Dis 1979;119:895-902.
8 Anthonisen NR, Wright EC, Hodgkins JE: Prognosis in chronic obstructive pulmonary disease. Am Rev Respir Dis 1986;133:14-20.

$\rightarrow 9$ Postma DS, Gimeno F, van der Weele LT, Sluiter HJ: Assessment of ventilatory variables in survival prediction of patients with chronic airflow obstruction: The importance of reversibility. Eur J Respir Dis 1985;67:360-368.

10 Almagro A, Calbo E, Ochoa de Echaguen A, Barreiro B, Quintana S, Heredia JL, Garau J: Mortality after hospitalization for COPD. Chest 2002;121:1441-1448.

-11 Seneff MG, Wagner DP, Wagner RP, Zimmerman JE, Knaus WA: Hospital and 1-year survival of patients admitted to intensive care units with acute exacerbation of chronic obstructive pulmonary disease. JAMA 1995;274: 1852-1857.

12 Connors AF, Dawson NV, Thomas C, Harrell FE Jr, Desbiens N, Fulkerson WJ, Kussin P, Bellamy P, Goldman L, Knaus WA: Outcomes following acute exacerbation of chronic obstructive lung disease. Am J Respir Crit Care Med 1996;154:959-967.

13 Memon A, Moody PM, Sugathan TN, ElGerges N, Al-Bustan M, Al-Shattia A, Al-Jazzaf $\mathrm{H}$ : Epidemiology of smoking among Kuwaiti adults: Prevalence, characteristics and attitudes. Bull WHO 2000;78:1306-1315.
14 Anthonisen NR, Manfreda J, Warren CP, Hershfield ES, Harding GK, Nelson NA: Antibiotic therapy in exacerbation of chronic obstructive pulmonary disease. Ann Intern Med 1987; 106:196-204.

15 Balter MS, Hyland RH, Low DE: Recommendations on the management of chronic bronchitis: A practical guide for Canadian Physicians. Can Med Assoc J 1994;157(suppl 10):5-23.

16 Kanner RE, Renzetti AD, Stannish WM, Barkman HW, Klanber MR: Predictor of survival in subjects with chronic airflow limitation. Am J Med 1983;74:249-255.

17 Vestbo J, Prescott E, Lange P, Schnohr P, Jensen G: Vital prognosis after hospitalisation for COPD: A study of random population sample. Resp Med 1998;92:772-776.

-18 Dewan NA, Rafique S, Kanwar B, Satpathy H, Ryschan K, Tillotson GS, Niederman MS: Acute exacerbation of COPD: Factors associated with poor treatment outcome. Chest 2000; 117:667-671.

19 Ball P, Harris JM, Lowson D, Tillotson G, Wilson R: Acute infective exacerbations of chronic bronchitis. QJM 1995;88:61-68. 
20 Garcia-Aymerich J, Farrero E, Felez MA, Izquierdo J, Marrades RM, Anto JM: Risk factors for readmission to hospital for a COPD exacerbation: A prospective study. Thorax 2003;58:100-105

21 American Thoracic Society: Standards for diagnosis and care of patients with COPD. Am J Respir Crit Care Med 1995;152:S77-S120.

22 US Surgeon-General 1984: The health consequences of smoking: Chronic obstructive lung disease. DHHS publication No 84-5020 J Washington, US Department of Health and Human Services, 1984.

23 Becklake MR: Chronic airflow limitations: Its relationship to work in dusty occupations. Chest 1988;88:608-617.

-24 Larson RK, Barman ML: The familial occurrence of chronic obstructive lung disease. Ann Intern Med 1965;63:1001-1008.

-25 Plank PK, Owen JL, Elliot MW: One year period prevalence study of respiratory acidosis in acute exacerbation of COPD: Implications for the provision of non-invasive ventilation and oxygen administration. Thorax 2000;55:550554.

-26 Gibson PG, Wlodarczyk JH, Wilson AJ, Sprogis A: Severe exacerbation of chronic obstructive airways disease: Health resource use in general practice and hospital. J Qual Clin Pract 1998;18:125-133.

-27 Thompson WH, Nielsen CP, Carvalho P, Charan NB, Crowley JJ: Controlled trial of oral prednisolone in out-patients with acute COPD exacerbation. Am J Respir Crit Care Med 1996;154:407-412.
28 Davies L, Angus RM, Calverley PM: Oral corticosteroids in patients admitted to hospital with exacerbation of chronic obstructive pulmonary disease: A prospective randomised controlled trial. Lancet 1999;354:456-460.

29 Niewoehner DE, Erbland ML, Deupree RH, Collins C, Gross NJ, Light RW, Anderson P, Morgan NA: Effect of systemic glucocorticoids on exacerbations of chronic obstructive pulmonary disease: Department of Veterans Affairs Co-operative Study Group. N Engl J Med 1999;340:1941-1947.

30 Kerstjens HAM, Brand PLP, Hughes M: A comparison of bronchodilator therapy with or without inhaled corticosteroid therapy for obstructive airways disease. N Engl J Med 1992; 327:1413-1419.

31 Dompeling E, van Schayck CP, van Grunsven PM, van Herwaarden CL, Akkermans R, Molema J, Folgering $\mathrm{H}$, van Weel C: Slowing the deterioration of asthma and chronic obstructive pulmonary disease observed during bronchodilator therapy by adding inhaled corticosteroids: A 4-year prospective study. Ann Intern Med 1993;118:770-778.

32 Garcia-Aymerich J, Monso E, Marrades RM, Escarrabill J, Felez MA, Sunyer J, Anto JM: Risk factors for hospitalization for a chronic obstructive pulmonary disease exacerbation. Am J Respir Crit Care Med 2001;164:10021007.
33 Long term domiciliary oxygen therapy in chronic hypoxic cor pulmonale complicating chronic bronchitis and emphysema. Report of the Medical Research Council Working Party. Lancet 1981;i:681-686.

34 Nocturnal Oxygen Therapy Trial Group: Continuous or nocturnal oxygen therapy in hypoxemic chronic obstructive lung disease: A clinical trial. Ann Intern Med 1980;93:391-398.

35 Johnson MK, Stevenson RD: Management of an acute exacerbation of COPD: Are we ignoring the evidence? Thorax 2002;57(suppl ii):1523

36 Poole PJ, Black PN: Oral mucolytic drugs for exacerbations of chronic obstructive pulmonary disease: Systematic review. BMJ 2001; 322:1271-1274.

37 Stey C, Steurer J, Bachmann S, Medici TC, Tramer MR: The effect of oral $\mathrm{N}$-acetylcysteine in chronic bronchitis: A quantitative systematic review. Eur Respir J 2000;16:253-262.

38 Vincken W, Van Noord JA, Greefhorst APM, Bantje TA, Kesten S, Korducki L, Cornelissen PJ: Dutch/Belgian Tiotropium Study Group: Improved health outcomes in patients with COPD during 1 year's treatment with tiotropium. Eur Respir J 2002;19:209-216.

39 Casaburi R, Mahler DA, Jones PW, Wanner A, San Pedro G, ZuWallack RL, Menjoge SS, Serby CW, Witek T Jr: A long-term evaluation of once-daily inhaled tiotropium in chronic obstructive pulmonary disease. Eur Respir J 2002;19:217-224 